\title{
Transactions Volume, Exchange Direction and Asymmetry of Volatility in Emerging Market: Evidence From Tunisian Stock Exchange
}

\author{
Jaber Yasmina ${ }^{1}$ \\ ${ }^{1}$ Higher Institute of Management of Gabes, Gabes University, Tunisia \\ Correspondence: Jaber Yasmina, Higher Institute of Management of Gabes, Gabes University, Rue Jilani Habib 6000, \\ Gabes, Tunisia.
}

Received: June 16, 2020

Accepted: July 27, 2020

Online Published: December 15, 2020

doi:10.5430/ijfr.v11n6p318

URL: https://doi.org/10.5430/ijfr.v11n6p318

\begin{abstract}
This study is an attempt to explain the relationship between intraday return and volume in Tunisian Stock Market. Indeed, former researches avow that the trading activity have the main explanatory power for volatility. However, most theories measure the activity of transactions through the size of exchange or the number of transactions. Nevertheless, these components are not aware enough of the importance of the direction of exchange when explaining the phenomenon of asymmetry of volatility. In the most of studies, the technique "Augmented Tick Test" (ATT) is employed so as to identify the direction of exchange. Such technique is adapted for the markets directed by orders like the Tunisian financial market. Again, this paper shows that the impact of the direction of exchange differs according to the market trend. In other words, if the returns are positive, the transactions of sale (of purchase) generate a decrease (increase) of volatility; whereas, they induce an increase (drop) of volatility if returns are negative. This result stresses the significance of exchange direction in explaning the asymmetry of volatility. Moreover, throughout this study, one may affirm that "Herding trades" are at the origin of the increase of volatility, while the "Contrarian trades" reduce volatility. Similarly, the identification of the direction of exchange enables us to affirm that the transactions of the initiates are characterized by the absence of returns auto- correlation; whereas, the transactions carried out by uninformed investors present an auto- correlation of the returns. In fact, the sign of this correlation varies according to transaction direction.
\end{abstract}

Keywords: asymmetry of volatility, transaction volume, exchange direction, orders directed market, contrarian trading, herding trading

\section{Introduction}

The study of the variation of equities price in the financial market has frequently been the focal point of researchers for decades. As a matter of fact, in order to apprehend this phenomenon well; several researches were devoted to the investigation of the relation between the motion of the prices and transaction activity by measuring the latter throughout the volume of transactions. Thus, a great deal of literature was interested in the study of volume and its association with the equity returns.

However, the volume of transactions can be measured by both their size and frequency. In fact, the price variations are primarily due to the exchanges of the informed investors who should negotiate orders of a particular size. Indeed, the initiates do not show any interest in exchanging big-sized orders so as to hide their identity. They, also, should not negotiate orders of small size because they are often more expensive than the other categories of size. Consequently, such investors had better exchange medium size orders. Thus, the dilemma concerning the informative contents between the size and the frequency of the transactions is worth being studied.

Most of researches assess the activity of transaction by the volume of exchange. But considered alone; volume of exchange, it can put some very important aspects out of sight since the direction of exchange cannot be perceived, i.e. whether there is a purchase or a sale. Noting, that each of these two trades holds its specific implications for the prices and liquidity. However, the volume of transactions is stoutly due to the pervasiveness of the transactions initiated into purchase or sale. In other words, the volume of transactions is always handed out between the sales and the purchases.

The theoretical and empirical researches have been focused on the study of the impact of the activity of transactions, measured by order imbalance, on the volatility of the equity returns. Indeed, imbalancing orders necessarily affects the 
equities prices since the market-maker will fight by fiddling with their prices in order to readjust his/ her inventory position. In this, the concept of imbalancing order is meaningful only in the case of a market with intermediary, where the market makers may control the pressure of the purchases and sales of the public.

In a market directed by orders, the absence of the market makers can weaken the role of order imbalance in the explanation of the volatilities of the equities returns. Thus, the exploration of the transactions direction proves to have a more important explanatory power over the volatility of the flows. In other words, the direction of exchanges can be a signal explaining the investor's interests in the exchange of the equity. However, since these interests are auto-correlated, it is intuitively suggested that a transaction of purchase is strongly followed by another transaction of purchase and vice versa. Thus, the direction of exchange will affect the future returns.

This review of literature arouses the interest to verify the impact of exchange direction and the volume of transaction on price volatility while trying to determine whether the size of transaction or the frequency of the exchanges that provides the best explanation to the volatility.

In fact, the stress falls on the aptitude of the transactions of purchases as well as of sales in explaining the phenomenon of asymmetry of the volatility. This enables us to recognize which of these transactions is the highest informative content and which is at the origin of volatility. In this, in order to go further into this research, we defined two classes of transactions; namely, "herding trades" (transactions carried out by the irrational investors) and "contrarian trades" (purchases or sales carried out by the rational investors). Then, we checked which of these transactions is at the origin of volatility. Moreover, the identification of the direction of exchange also helps us to determine the impact of the transactions carried out by the informed investors as well as those achieved by the uninformed investors on return volatility.

\section{Literature Review}

The volatility of returns is a basic element in finance. So, the studies concerning equities pricing, the risk management, the capital allocation, and the tests of the efficiency market use volatility as a basis for the development of their analyses. Consequently, volatility was largely studied according to several dimensions. Volatility in finance is modelled, according to Engel (1982), by the autoregressive conditional heterosedastic models (ARCH) and the GARCH models developed by Bollerslev (1986).

Several studies, such as Schwert (1989), Pramod Kumar Naik \& Rangan Gupta \& Puja Padhi (2018) ...... tried to recognize the factors determining volatility. Most researches showed that the asymmetry of volatility is strongly related to the frequency of the daily transactions. French and Roll (1986) affirm that the transactions are the cause of volatility. Thus, the asymmetry of volatility must be the outcome of the transaction process.

\subsection{The Direction of Exchange and the Asymmetry of Volatility}

According to Hu and Chan (2000) if the purchase orders are higher than the sales orders, the transaction is qualified as an initiated purchase: this implies a strong probability that the investors received good information. In contrast, if the sales orders are higher than the purchase orders, the transaction is qualified as an initiated sale: this implies a strong probability that the investors received bad information. Thus, the direction of exchange is a reliable indicator for the investors as it enables them to know the nature of the transmitted information. Consequently, the direction of exchange affects the behaviour of the investors and leads to the volatility of the equities flows.

Additionally, most of the empirical works, such as those carried out by Choi, Salandro and Shastri (1988) and YC Wang, JL Wu, YH Lai (2018) show that the advent of the sale and purchase orders is not completely arbitrary. Indeed, the purchase orders tend to be followed by purchase orders and the sale orders are followed by other sale orders. This phenomenon of persistence of the direction of the orders affects the prices. Accordingly, the persistence of the direction of the transactions influences the volatility of returns.

Obviously, the literature stresses the fact that when the last returns are negative (positive), the transactions of sale are at the origin of the increase (the fall) of the subsequent volatility. The same principle is applied to the transaction of purchases. This suggests that the sales and purchases represent the origin of the volatility asymmetry.

The empirical obviousness stipulates that the asymmetry of volatility presents a strong variation in time. Indeed, the asymmetry of volatility is measured by the coefficient of regression of the daily volatility with the last returns which vary with the sales activity (of purchase). Explicitly, the sales activity (of purchase) makes it possible to grasp the negative effect (positive) on the volatility of returns. 


\section{2 «Herding Trades» and «Contrarian Trades»}

Friedman (1953) showed that the irrational investors destabilize the prices by buying when the prices are raised and selling when the prices are low; whereas, the rational investors, who try to speculate, they buy when the prices are low and sell when the prices are high and have the flows vary against the deviation of the prices from their fundamental values and, consequently, they stabilize the prices. In this context, the "herding" transactions are carried out conversely with what must normally be according to the true information and, consequently, generate an increase in volatility.

Thus, the activity of transactions can be divided into two elements: "herding" transactions and "contrarian" transactions. The "contrarian" transactions are defined as the transactions of sales (of purchases) when the returns are positive (negative); whereas, the "herding" transactions are the transactions of sales (purchases) when the returns are negative (positive). The "herding" transactions bring about an increase in volatility, whereas the "contrarian" transactions let volatility fall. Avramov, Chordia and Goyal (2006) Dwang (2008) and P Corredor, S Ferreruela (2012) shows that if the prices go down, the "herding trades" control and increase volatility; whereas, if the prices increase, the "contrarian trades" lead to a fall of volatility. Accordingly, the activity of the "contrarian" and the "herding" transactions explains the asymmetry of volatility.

\section{Identification of the Direction of Exchange}

In this research, a new approach is presented in order to identify the direction of exchange. Such approach allows acknowledging the effect of information on an order listed market. Indeed, a great deal of literature uses the Bid-Ask quotation to distinguish the transactions initiated into purchase from those initiated into sale. Indeed, in an order-oriented market, the orders are subjected to the basis of the available information, but these orders do not directly involve the transactions. Therefore, the use of the Bid-Ask quotation law is not appropriate to the detection of the transactions as well as their directions in such a market. Moreover, in order-oriented markets, the cause of the release of the transactions cannot be determined since the execution of the transactions and the liquidation of the orders do not depend on the arrival of any special order. Moreover, in these markets, there are no market-makers and the quotations stem from the investors. However, as the purchasers as well as the salesmen can have private information, one cannot suppose that the last order comprises the best information. So, the use of the Bid-Ask quotation is not appropriate to such markets like the Tunisian financial market.

In a market directed by orders, the sale and purchase orders are gathered over a period. When the notebooks of orders are liquidated, each one pays or receives a price on the basis of his quotation. According to the mechanism of the flow of transactions, it is neither possible nor logical to know which order is related to the transaction. Accordingly, a new definition of the direction of orders is appropriate to these markets. This definition is based on the sign of the net orders which occur between two transactions. If the purchase orders, arriving between two transactions, are higher than the sale orders, one can say that the transactions of purchase are dominant and the sign of the direction of exchange will be positive. Thus, a large purchase order implies a strong probability that the investors receive good information and vice versa. However, the net order can be positive or negative according to the various prices. The net order can be evaluated according to the most recent price of transactions since the latter reflects the majority of the most recent information. Since the set of orders is not perceptible to the investors, they cannot know the net order directly. Therefore, to measure the direction of exchange, one must use the information available for the investors.

Thus, we will follow the same step elaborated by Hu and Chang (2000), called "Augmented Tick Test" (ATT). The rule of this technique is presented as follows:

$\checkmark \quad$ If the price of the current transaction is higher than the preceding price (uptick), then the current transaction is qualified as dominated by the purchases and the direction of exchange is positive.

$\checkmark \quad$ If the price of the current transaction is lower than the preceding price (downtick), then the current transaction is qualified as dominated by sales and the direction of exchange is negative.

$\checkmark \quad$ If the price of the current transaction is equal to the preceding price, then the direction of exchange depends on the best Bid-Ask quotation. The step is presented as follows:

- If the price of the current transaction is equal to thebest Bid, so the direction of exchange is positive

- If the price of the current transaction is equal to the best Ask, so the direction of exchange is negative

- If the price of the current transaction fluctuates between Bid and Ask, the direction of exchange cannot be defined. 


\section{Presentation and Explanation of the Model}

With reference to the works of Y Ni, YC Liao, P Huang (2015) and YC Wang, JL Wu, YH Lai (2018), we will try to analyze the impact of transaction activity and exchange direction on equities volatility.

For this purpose, we will go through four stages. Initially, we start with the extraction of volatility. Then, we will study the impact of purchase and sale transactions on the asymmetry volatility. The third stage aims at the exploration of the relation between "Herding \& contrarian trades" and the volatility of returns. Finally, we check the effect of the transactions of the informed and uninformed investors on volatility.

\subsection{Estimation of Volatility}

In order to estimate the values of the returns volatility, we regressed the daily returns of the equities as follows:

$$
\begin{aligned}
& R_{i t}=\sum_{k=1}^{5} \alpha_{i k} D_{k t}+\sum_{k=1}^{12} \beta_{i k} R_{i, t-k}+\gamma_{i} \frac{N S_{i t}}{N T_{i t}}+\varepsilon_{i t} \\
& R_{i t}=\sum_{k=1}^{5} \alpha_{i k} D_{k t}+\sum_{k=1}^{12} \beta_{i k} R_{i, t-k}+\gamma_{i} \frac{N B_{i t}}{N T_{i t}}+\varepsilon_{i t}
\end{aligned}
$$

Such that:

$R_{i t}$ : Capital gain returns of the $\mathrm{i}^{\text {th }}$ share in the date $\mathrm{t}$

$$
R_{i t}=[\text { closed price }(t)-\text { closed price }(t-1)]+\operatorname{dividends}(t) /[\operatorname{closed} \text { price }(t-1)]
$$

$D_{k t}$ : The dummy variable which represents the business days of the week.

$N S_{i t}\left(N B_{i t}\right)$ : the sales transactions (of purchases) measured by the number of the sales (purchases) transactions or the number of the sold (bought) equities.

$N T_{i t}$ : The total numbers of transactions or the whole exchanged volume for the equity $\mathrm{i}$ and the day $\mathrm{t}$.

$\frac{N S_{i t}}{N T_{i t}}\left(\frac{N B_{i t}}{N T_{i t}}\right)$ : is the report of the sales transactions (of purchase) divided by the total transactions.

Thus, the use of the two measures of the transaction volume (by number and size) is an attempt to know whether the frequency of transactions or the size of exchange provides the best explanatory power to the price volatility.

The goal of the two first regressions is to estimate the values of the volatility measured by the absolute value of the residue of equations (1) and (1').

\subsection{The Impact of the Transactions of Purchases and the Transactions of Sales}

The main objective is to highlight the ability of the transactions of purchases and sales in explaining the asymmetry of volatility. So, in order to determine the impact of transaction activity and exchange direction on volatility, we choose to regress to the following equations:

$$
\begin{aligned}
& \left|\varepsilon_{i t}\right|=\phi_{i}+\psi_{i} M_{t}+\sum_{k=1}^{12} \rho_{i k}\left|\varepsilon_{i, t-k}\right|+\varphi_{i} N T_{i t}+\left(\delta_{i 0}+\delta_{i 1} \frac{N S_{i, t-1}}{N T_{i, t-1}}\right) \varepsilon_{i, t-1}+\eta_{i t} \\
& \left|\varepsilon_{i t}\right|=\phi_{i}+\psi_{i} M_{t}+\sum_{k=1}^{12} \rho_{i k}\left|\varepsilon_{i, t-k}\right|+\varphi_{i} N T_{i t}+\left(\delta_{i 0}+\delta_{i 1} \frac{N B_{i, t-1}}{N T_{i, t-1}}\right) \varepsilon_{i, t-1}+\eta_{i t}
\end{aligned}
$$

Such that: 
$M_{t}:$ is the dummy variable that represents Monday.

$\left|\varepsilon_{i, t-k}\right|:$ The previous volatility that allows for the recognition the persistence of volatility.

4.3 The Impact of "Herding Trades" and "Contrarian Trades"

The third stage consists in determining the impact of the "herding trades" and "contrarian trades" on the future volatility. Hence, the transactions of sales are divided in two parts: "Herding sell trades" and "contrarian sell trades". Indeed, the "Contrarian sell trades" are usually defined as the transaction of sale when the returns are positive. Accordingly, they are stated as:

- $\quad \frac{N S_{i t}}{N T_{i t}} *\left(\varepsilon_{i t} \geq 0\right)$, such that $\left(\varepsilon_{i t} \geq 0\right)$ is a dummy variable equal to one if the returns are positive, otherwise it is equal to zero.

"Herding sell trades" are also a sale transaction but when the returns are negative, they are stated as:

- $\frac{N S_{i t}}{N T_{i t}} *\left(\varepsilon_{i t} \prec 0\right)$ such that $\left(\varepsilon_{i t} \prec 0\right)$ is a dummy variable equal to one if the returns are negative and zero otherwise.

Thus, the sales accompanied by a fall of the prices indicate "herding sell trades", whereas those accompanied by an increase in price represent "contrarian sell trades".

In the same way, the transactions of purchases are divided in two components: "Herding buy trades" and "contrarian buy trades". The "Contrarian buy trades" are a transaction of purchase when the returns are negative and are stated as follows:

- $\frac{N B_{i t}}{N T_{i t}} *\left(\varepsilon_{i t} \prec 0\right)$ such that $\left(\varepsilon_{i t} \prec 0\right)$ is a dummy variable equal to one if the returns are negative, otherwise it is equal to zero.

"Herding buy trades" are also a transaction of purchase but when the returns are positive, it is given by:

- $\frac{N B_{i t}}{N T_{i t}} *\left(\varepsilon_{i t} \geq 0\right)$ such that $\left(\varepsilon_{i t} \geq 0\right)$ is a dummy variable equal to one if the returns are positive, otherwise it is equal to zero.

Thus, the purchases accompanied by a rise in prices indicate "herding buy trades", whereas those accompanied by price drops present "contrarian buy trades".

After identifying the "herding \& contrarian trades", we will recognize the impact of these two components on the volatility by referring to the following equations:

$$
\left|\varepsilon_{i t}\right|=\phi_{i}+\psi_{i} M_{t}+\sum_{k=1}^{12} \rho_{i k}\left|\varepsilon_{i, t-k}\right|+\varphi_{i} N T_{i, t}
$$




$$
\begin{aligned}
& +\left[\delta_{i 0}+\delta_{i 1}^{\frac{N S_{i, t-1}}{N T_{i, t-1}} *\left(\varepsilon_{i, t-1} \geq 0\right)}+\delta_{\text {CONTRARIAN }}^{\frac{N S_{i, t-1}}{N T_{i, t-1}} *\left(\varepsilon_{i, t-1} \prec 0\right)}\right] \underbrace{}_{\text {HERDING }} \underbrace{}_{i, t-1}+\eta_{i t} \\
& \left|\varepsilon_{i t}\right|=\phi_{i}+\psi_{i} M_{t}+\sum_{k=1}^{12} \rho_{i k}\left|\varepsilon_{i, t-k}\right|+\varphi_{i} N T_{i, t} \\
& +\left[\delta_{i 0}+\delta_{i 1}^{\frac{N B_{i, t-1}}{N T_{i, t-1}} *\left(\varepsilon_{i, t-1} \geq 0\right)}+\delta_{\text {HERDING }}^{\frac{N B_{i, t-1}}{N T_{i, t-1}} *\left(\varepsilon_{i, t-1} \prec 0\right)}\right] \underbrace{}_{\text {CONTRARIAN }} \underbrace{}_{i, t-1}+\eta_{i t}
\end{aligned}
$$

For sale transactions, the sum of $\delta_{i 1}$ and $\delta_{i 2}$ must be lower than zero $\left(\delta_{i 1}+\delta_{i 2} \prec 0\right)$. In fact, as it is stated before that the "herding sell trades" lead to an increase in volatility, whereas the "contrarian sell trades" generate a reduction of volatility. So, $\delta_{i 1}$ and $\delta_{i 2}$ must have a negative sign. This is explained by the fact that the "herding sell trades" multiplied by $\varepsilon_{i, t-1} \prec 0$ are supposed to increase the volatility of the flows, so $\delta_{i 2}$ must be inferior to zero. Likewise, the "contrarian sell trades" associated with $\varepsilon_{i, t-1} \geq 0$ reduce the volatility so $\delta_{i 1}$ must be lower than zero.

For the transactions of purchases $\delta_{i 1}$ and $\delta_{i 2}$ have to be positive ( $\delta_{i 1} \succ 0$ et $\delta_{i 2} \succ 0$ ). In fact, recalling that the "herding buy trades" lead to an increase in volatility, so the "contrarian buy trades" generate a reduction of volatility. This explains the sign of the coefficients. In fact, since the "contrarian buy" transactions multiplied by $\varepsilon_{i, t-1} \prec 0$ are supposed to reduce the flows volatility, so $\delta_{i 2}$ must be higher than zero. Also the "contrarian buy trades" with $\varepsilon_{i, t-1} \geq 0$ increase the volatility, so $\delta_{i 1}$ must be higher than zero.

\subsection{The Impact of the Transactions of the Initiates and Transactions of the Uninformed Investors}

In order to distinguish the impact of the informed investor's transactions from those of the uninformed investors and to detect their effects on the volatility of the flows, we will follow the same aproach developed by Pramod Kumar Naik \& Rangan Gupta \& Puja Padhi (2018) and Avramov, and Chordia and Goyal (2006). Indeed, these researchers affirm that the equities flows should not change owing to the transactions of the informed investors. In other words, the variation of the prices is not due to a former exchange of an informed investor but rather due to a previous exchange carried out by the uninformed investors (or for liquidity reason trading). Thus, Campbell, Grossman and Wang (1993) assume that the pressure of the sales carried out by the uninformed investors lead to a temporary fall of the prices. This temporary fall will be reversed if the sales are carried out by the initiates. This affirms that the transactions of purchases or sales followed by a change of the equities prices are qualified as uninformed transactions (or for liquidity reason). In this, 
Hellwig (1980), Wang (1993) and Avramov, Chordia and Goyal (2008) show that the transactions of the uninformed investors lead to an increase in volatility, whereas the transactions of the initiates decrease volatility.

Therefore, an auto-correlation test will be employed so as to determine the effect of the transactions carried out by the initiates and those of the uninformed investors on volatility. According to the explanation mentioned above, the last transactions of the informed investors are independent of the future returns of the equities. In other words, there is no auto- correlation between the future returns and the last returns related to the transactions of the informed investors. But there is an auto- correlation between the future and the last returns due to the transactions carried out by the uninformed investors.

The correlation test is carried out by using:

$$
\begin{aligned}
& \varepsilon_{i, t+1}=\phi_{i}+[\psi_{i} M_{t}+\delta_{i, 0} T_{u r n}+\delta_{i, 1} \underbrace{\frac{N S_{i t}}{N T_{i t}} *\left(\varepsilon_{i t} \geq 0\right)}_{\text {inf } \text { ormed }}+\delta_{i, 2} \underbrace{N S_{i t} *\left(\varepsilon_{i t} \prec 0\right)}_{\text {uninf ormed }}] \varepsilon_{i t}+\mu_{i t+1}
\end{aligned}
$$

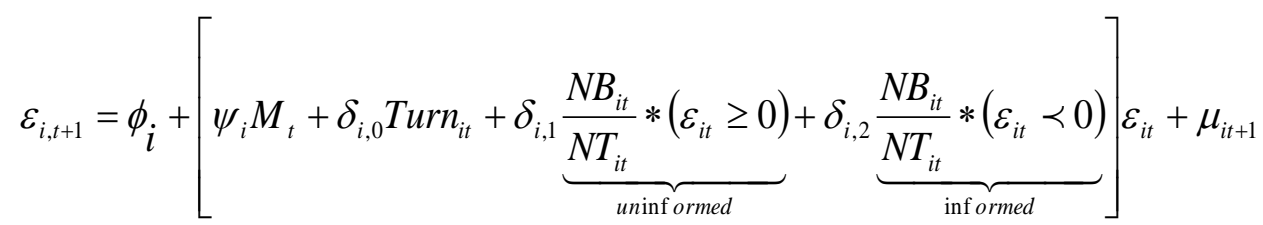

Such that

$\operatorname{Turn}_{i t}$ : represents the capitalization of the equity $\mathrm{i}$ at the date $\mathrm{t}$, it is included in this regression in order to control this variable since it contributes to an inversion of the returns.

$\frac{N S_{i t}}{N T_{i t}} *\left(\varepsilon_{i t} \geq 0\right)\left(\frac{N B_{i t}}{N T_{i t}} *\left(\varepsilon_{i t} \prec 0\right)\right)$ : represents the informed transactions. So, $\delta_{1}\left(\delta_{2}\right)$ must be insignificant since the basic idea stipulates that there is an absence of the auto- correlation of the returns when the transactions are due to an initiates trades.

$\frac{N S_{i t}}{N T_{i t}} *\left(\varepsilon_{i t} \prec 0\right)\left(\frac{N B_{i t}}{N T_{i t}} *\left(\varepsilon_{i t} \geq 0\right)\right)$ : represents the transactions of the uninformed investors. $\delta 2\left(\delta_{1}\right)$ must be significant in order to characterize the presence of an auto- correlation between the returns of the equities exchanged by the uninformed investors.

\section{Data}

Throughout this research, we try to make an application to the Tunisian financial market since it represents a new field of investigation regarding the nature of its organization. The sample period covers 13 months from February 2018 to February 2019. Around 280 business days.

The data retained are:

- The prices and volumes of the intra-daily transactions as well as the Bid-Ask quotations necessary for the identification of the direction of exchange.

- The daily closing prices used for calculate the daily returns.

- The number of the transactions carried out per day which measures the frequency of the transactions.

- The daily quantity exchanged which measures the size of exchange. 
- The stock-market capitalization of the security i during the day t.

6. The Descriptive Statistics

\begin{tabular}{|c|c|c|c|c|c|c|c|}
\hline Equity & $\begin{array}{l}\text { Average } \\
\text { return }\end{array}$ & $\begin{array}{l}\text { Average } \\
\text { total volume } \\
\text { per } \\
\text { transaction }\end{array}$ & $\begin{array}{l}\text { Average } \\
\text { volume of } \\
\text { transaction } \\
\text { of purchase }\end{array}$ & $\begin{array}{l}\text { Average } \\
\text { volume of } \\
\text { transaction } \\
\text { of sale }\end{array}$ & $\begin{array}{l}\text { Average } \\
\text { total } \\
\text { number of } \\
\text { transaction }\end{array}$ & $\begin{array}{l}\text { Average } \\
\text { number of } \\
\text { transaction } \\
\text { of purchase }\end{array}$ & $\begin{array}{l}\text { Average } \\
\text { number of } \\
\text { transactions } \\
\text { of sale }\end{array}$ \\
\hline$B T$ & $0.19 \%$ & 2975.3497 & 886.81414 & 2088.5355 & 46.7423 & 7.7829 & 38.9782 \\
\hline$B S$ & $0.157 \%$ & 21022.325 & 9268.546 & 11753.774 & 41.92901 & 20.060119 & 21.86883 \\
\hline BIAT & $0.315 \%$ & 9513.8162 & 5369.7353 & 4144.0788 & 21.07123 & 8.596866 & 12.48029 \\
\hline$B H$ & $0.366 \%$ & 9562.8140 & 5417.5233 & 4145.2638 & 26.82168 & 11.37586 & 15.44581 \\
\hline BTEI & $0.0862 \%$ & 3150.5903 & 1071.2267 & 2079.3635 & 26.1038 & 11.09868 & 15.00512 \\
\hline MAGASIN & $0.0513 \%$ & 6511.4636 & 3277.5496 & 3233.9139 & 39.46631 & 17.44744 & 22.01887 \\
\hline GENERAL & $0.530 \%$ & 3428.3583 & 1753.4260 & 1674.9322 & 31.01436 & 14.83897 & 16.17538 \\
\hline MONOPRIX & $0.020 \%$ & 3697.6636 & 2447.414 & 1250.2496 & 36.13823 & 21.11287 & 15.02902 \\
\hline$S F B T$ & $-0.0599 \%$ & 3146.4789 & 776.7979 & 2369.6809 & 21.899 & 8.770430 & 13.12903 \\
\hline SIAME & $0.144 \%$ & 3854.1697 & 2208.3134 & 1645.8562 & 30.64086 & 13.88447 & 16.75984 \\
\hline SIPHAT & $0.0959 \%$ & 25824.517 & 15675.681 & 10148.835 & 42.75072 & 20.12320 & 22.62753 \\
\hline SOMOCER & $0.0135 \%$ & 3404.8879 & 1755.8316 & 1649.0562 & 30.52731 & 15.32050 & 15.20680 \\
\hline SOTETEL & $0.0679 \%$ & 2972.4615 & 1700.2554 & 1272.2060 & 20.85954 & 9.710687 & 11.14885 \\
\hline $\begin{array}{l}\text { SPDIT } \\
\text { STB }\end{array}$ & $0.0158 \%$ & 9803.0580 & 4974.7636 & 4828.2943 & 27.15992 & 13.62068 & 13.53924 \\
\hline
\end{tabular}

These values are daily averages calculated along the study period.

One may note that the companies are characterized by a wide range of volume of transactions and a large number of transactions. In fact, the highest transactions volume corresponds to "Somocer"; whereas, the weakest one is related to the "Banque de Tunisie". However, the company having the highest number of transactions is the "Banque de Tunisie" unlike the "Spdit" company which has the lowest number of transactions. The scale of the activity of the equities is very broad because the most exchanged equity witnesses' more than twenty five thousand transactions on average per day versus less than three thousand transactions for the least treated company. Moreover, one may also notice that the most exchanged company is not the same company that is the most frequently treated. Also, one may note that the company that is the most frequently exchanged is the same company having the lowest volume of transactions. This enables us to affirm that the investors are averse to the risk since they prefer splitting their big-sized exchanges into several little-sized transactions. In this respect, Admati and Pfleiderer (1988) assert that the sound-effects investors (who exchange small quantities) outnumber the informed investors (who exchange small quantities). This assertion enables us to qualify the majority of the Tunisian investors as sound-effects investors. What is more, one may also note that the volume of purchasing transactions is higher than that of the transactions of sale for the majority of the equities included in the sample at hand. In contrast, the number of transactions of sales is higher than the number of transactions of purchases. This highlights the camouflage strategy adopted by the Tunisian investors. Thus, one should also note that the average returns of all the equities are positive (except for the "Siame" company). Again, the values of these returns are relatively weak compared with the returns of equities in other stock exchanges.

\section{Results and Interpretations}

The results show that the statistics of Durbin and Watson are close to each other. That is what enables us to affirm the absence of errors auto- correlation. Whence, the estimators of MCO converge asymptotically towards the true values of the parameters with a minimal variance. 
Moreover, the results of the test of Dickey and Fuller Augmented "ADF" applied to all the variables and the equities of our sample show that all the variables are stationary. Accordingly, it becomes possible to establish an equilibrium relation between these variables and to carry out the regressions by the ordinary last squares.

\subsection{Results of the Volatility Estimation}

The regression of the equations (1) and (1') enables us to estimate the values of volatility. The results of this regression are presented by Table 1 .

Table 1. Volatility estimation

\begin{tabular}{|c|c|c|c|c|c|c|}
\hline & \multicolumn{3}{|c|}{$R_{i t}=\sum_{k=1}^{5} \alpha_{i k} D_{k t}+\sum_{k=1}^{12} \beta_{i k} R_{i, t-k}+\gamma_{i} \frac{N S_{i t}}{N T_{i t}}+\varepsilon_{i t}$} & \multicolumn{3}{|c|}{$R_{i t}=\sum_{k=1}^{5} \alpha_{i k} D_{k t}+\sum_{k=1}^{12} \beta_{i k} R_{i, t-k}+\gamma_{i} \frac{N B_{i t}}{N T_{i t}}+\varepsilon_{i}$} \\
\hline & $\alpha_{i 1}$ & $\gamma_{i}$ & $D W$ & $\alpha_{i 1}$ & $\gamma_{i}$ & $D W$ \\
\hline$B T$ & $\begin{array}{l}0.00077 \\
(3.17079)^{*}\end{array}$ & $\begin{array}{l}-0.000928 \\
(-3.44475)^{*}\end{array}$ & 2.000978 & $\begin{array}{l}-0.000159 \\
(-0.7070)\end{array}$ & $\begin{array}{l}0.000928 \\
(3.44475)^{*}\end{array}$ & 2.000978 \\
\hline$B S$ & $\begin{array}{l}0.005619 \\
(3.73332)^{*}\end{array}$ & $\begin{array}{l}-0.006758 \\
(-3.44628)^{*}\end{array}$ & 2.0006635 & $\begin{array}{l}-0.001139 \\
(-0.8194)\end{array}$ & $\begin{array}{l}0.006758 \\
(3.44628)^{*}\end{array}$ & 2.006635 \\
\hline BIAT & $\begin{array}{l}0.001626 \\
(3.696907)^{*}\end{array}$ & $\begin{array}{l}-0.001890 \\
(-3.54025)^{*}\end{array}$ & 1.999403 & $\begin{array}{l}-0.000242 \\
(-0.5693)\end{array}$ & $\begin{array}{l}0.001843 \\
(3.444263)^{*}\end{array}$ & 1.998893 \\
\hline BH & $\begin{array}{l}0.001269 \\
(2.330517)^{*}\end{array}$ & $\begin{array}{l}-0.002310 \\
(-3.012083)^{*}\end{array}$ & 2.003622 & $\begin{array}{l}-0.001074 \\
(-1.965573)\end{array}$ & $\begin{array}{l}0.002375 \\
(3.083585)^{*}\end{array}$ & 2.004822 \\
\hline BTEI & $\begin{array}{l}0.000622 \\
(1.1475293)\end{array}$ & $\begin{array}{l}-0.001104 \\
(-2.141586)^{*}\end{array}$ & 2.004716 & $\begin{array}{l}-0.000481 \\
(-1.197118)\end{array}$ & $\begin{array}{l}0.001104 \\
(2.141586)^{*}\end{array}$ & 2.004816 \\
\hline $\begin{array}{l}\text { MAGASIN } \\
\text { GENERAL }\end{array}$ & $\begin{array}{l}0.002745 \\
(3.163887)^{*}\end{array}$ & $\begin{array}{l}-0.004734 \\
(-4.011789)^{*}\end{array}$ & 2.001450 & $\begin{array}{l}-0.001950 \\
(-2.303750)^{*}\end{array}$ & $\begin{array}{l}0.004650 \\
(3.939851)^{*}\end{array}$ & 2.001927 \\
\hline MONOPRIX & $\begin{array}{l}0.001513 \\
(1.815962)\end{array}$ & $\begin{array}{l}-0.002297 \\
(-2.245941)^{*}\end{array}$ & 2.013833 & $\begin{array}{l}-0.000784 \\
(-0.971500)\end{array}$ & $\begin{array}{l}0.002297 \\
(2.24549)^{*}\end{array}$ & 2.013833 \\
\hline SFBT & $\begin{array}{l}0.000115 \\
(0.686930)\end{array}$ & $\begin{array}{l}-0.0000793 \\
(-0.333157)\end{array}$ & 1.999395 & $\begin{array}{l}0.0000355 \\
(0.199418)^{*}\end{array}$ & $\begin{array}{l}0.0000793 \\
(0.333157)\end{array}$ & 1.999395 \\
\hline SIAME & $\begin{array}{l}0.002787 \\
(4.112057)^{*}\end{array}$ & $\begin{array}{l}-0.004305 \\
(-5.624513)^{*}\end{array}$ & 1.987613 & $\begin{array}{l}-0.001518 \\
(-2.984528)^{*}\end{array}$ & $\begin{array}{l}0.004305 \\
(5.624513)^{*}\end{array}$ & 1.987613 \\
\hline SIPHAT & $\begin{array}{l}0.001204 \\
(3.950005)^{*}\end{array}$ & $\begin{array}{l}-0.002165 \\
(-5.210226)^{*}\end{array}$ & 1.978714 & $\begin{array}{l}-0.000961 \\
(-3.121606)^{*}\end{array}$ & $\begin{array}{l}0.002165 \\
(5.210268)^{*}\end{array}$ & 1.978714 \\
\hline SOMOCER & $\begin{array}{l}0.004628 \\
(3.471858)^{*}\end{array}$ & $\begin{array}{l}-0.005187 \\
(-3.2836)^{*}\end{array}$ & 2.003223 & $\begin{array}{l}-0.000558 \\
(-0.521109)\end{array}$ & $\begin{array}{l}0.005187 \\
(3.2836)^{*}\end{array}$ & 2.003223 \\
\hline SOTETEL & $\begin{array}{l}0.000946 \\
(3.554228)^{*}\end{array}$ & $\begin{array}{l}-0.001662 \\
(-4.563813)^{*}\end{array}$ & 2.001876 & $\begin{array}{l}-0.000716 \\
(-2.744344)^{*}\end{array}$ & $\begin{array}{l}0.001662 \\
(4.564638)^{*}\end{array}$ & 2.001865 \\
\hline SPDIT & $\begin{array}{l}0.001686 \\
(2.420416)^{*}\end{array}$ & $\begin{array}{l}-0.003806 \\
(-4.266116)^{*}\end{array}$ & 1.997643 & $\begin{array}{l}-0.002120 \\
(-2.867012)^{*}\end{array}$ & $\begin{array}{l}0.003806 \\
(4.266116)^{*}\end{array}$ & 1.997643 \\
\hline$S T B$ & $\begin{array}{l}0.0000868 \\
(0.169198)\end{array}$ & $\begin{array}{l}-0.000848 \\
(-1.377612)\end{array}$ & 1.999978 & $\begin{array}{l}-0.000608 \\
(-1.208333)\end{array}$ & $\begin{array}{l}0.000532 \\
(0.863184)\end{array}$ & 2.000376 \\
\hline $\begin{array}{l}\text { Results of the } \\
\text { panel }\end{array}$ & $\begin{array}{l}0.006617 \\
(1.925642)\end{array}$ & $\begin{array}{l}-0.002810 \\
(-7.990070)^{*}\end{array}$ & 2.005747 & $\begin{array}{l}-0.007620 \\
(-2.220369)^{*}\end{array}$ & $\begin{array}{l}0.002810 \\
(7.990070)^{*}\end{array}$ & 2.005747 \\
\hline
\end{tabular}

* Indicate the significant result. 
We note a Monday effect for $72 \%$ of the equities of our sample if the transactions are initiated sales. In this case, the Monday effect affects the equities returns positively, which is the reverse of what is expected. This is translated by the fact that the sales transactions, on Mondays, increase the equities flows and, consequently, increase the returns. Nevertheless, this effect is significant only for $36 \%$ of the equities if there are initiated purchases. Thus, it is noticed that all the coefficients relating to the variable Monday are negative. Therefore, the purchases, on Mondays, negatively affect the equities returns. This result is explained by the fact that the accumulation of information during the weekends, followed by sales or purchases, can disturb the market which needs time to disseminate this pile of information.

The analysis of results shows a significant relation between the transactions of sale and the returns of the equities; this relation is also significant for the transactions of purchase. However, the direction of this relation varies according to the direction of exchange.

Indeed, the relation between the transactions of purchases and the returns is significantly positive. This result means that the purchases involve an increase in the returns. In other words, the transactions of purchases make the prices of the equities increase. This corroborates the intuition suggested by Chan and $\mathrm{Hu}$ (2000) who stipulate that the transactions of purchases imply a strong probability that the investors received good news and, consequently, have positive returns.

However, if there are transactions of sales, the relation with the returns will be reversed and become negative. Thus, the initiated sales affect the returns negatively. Indeed, the sales represent a bad signal for the investors, i.e. the investors have bad information and generate, thereafter, a fall of the equities flows. As a result, the returns will be negative. Similarly, this result coincides with the predictions of Chan and $\mathrm{Hu}(2000)$.

These results are related to the measurement of the activity of exchange (the total exchange, transactions of purchases and transactions of sales) by the number of the exchanged equities, i.e. by the volume of transactions. Even if we measure the activity of transactions by the number of transactions, i.e. by the frequency of transactions, we will have the same results. This is to say that the coefficient of adjustment is higher than the regressions which choose the measurement of the activity of transactions by the frequency of exchanges. Accordingly, one can proclaim that the frequency of transactions comprises an informational component more important than that of the volume of exchange. Thus, the frequency provides a better explanatory capacity over the returns than that provided by volumes. These results corroborate the conclusions of Jones, Kaul and Lipson (1994) and Chan and Fong (2000).... who affirm that the impact of the size of exchange on the returns of the equities weakens after the control of the variable frequency of transactions.

The panel analysis confirms the individual analysis and shows that the relation between the returns and the activity of transaction varies according to the direction of exchange.

Obviously, these results justify the importance of the direction of exchange in the explanation of the returns of the equities, since, according to Choi, Salandro and Shastri (1988) and Hasbrouk (1991), the arrival of the sale and purchase orders is not completely random and the persistence of the direction of the orders affects the prices. Also, each direction of order holds specific implications on the behaviour of the investors and, consequently, on the flows of the equities.

Moreover, it should be noted that in addition to the analysis of the relation between the returns and the direction of exchange, the introduction of the variables $\frac{N S_{i t}}{N T_{i t}}$ and $\frac{N B_{i t}}{N T_{i t}}$ in this regression is to ensure an orthogonality between

the non- anticipated returns (measured by $\varepsilon_{i t}$ ) and these variables in the next regression. What paves us the way to make a reassuring interpretation of the coefficients relative to these variables when explaining the relation between volatility and the non-anticipated returns.

\subsection{The Relation Between Volatility and the Exchange Activity}

In order to find out the effect of the volume of transactions on the volatility of the flows and to affirm the power of the transactions of purchase and sales in the explanation of the asymmetry of volatility, the regressions of the equations (2) and (2') are achieved. The results are presented in Table 2. 
Table 2 . The relation between volatility and exchange activity

$$
\left|\varepsilon_{i t}\right|=\phi_{i}+\psi_{i} M_{t}+\sum_{k=1}^{12} \rho_{i k}\left|\varepsilon_{i, t-k}\right|+\varphi_{i} N T_{i t}+\left(\delta_{i 0}+\delta_{i 1} \frac{N S_{i, t-1}}{N T_{i, t-1}}\right) \varepsilon_{i, t-1}+\eta_{i t} \quad\left|\varepsilon_{i t}\right|=\phi_{i}+\psi_{i} M_{t}+\sum_{k=1}^{12} \rho_{i k}\left|\varepsilon_{i, t-k}\right|+\varphi_{i} N T_{i t}+\left(\delta_{i 0}+\delta_{i 1} \frac{N B_{i, t-1}}{N T_{i, t-1}}\right) \varepsilon_{i, t-1}+\eta_{i t}
$$

$\begin{array}{cccccccc}\varphi_{i} & \delta_{i 0} & \delta_{i 1} & \boldsymbol{D W} & \varphi_{i} & \delta_{i 0} & \delta_{i 1} & \boldsymbol{D W}\end{array}$

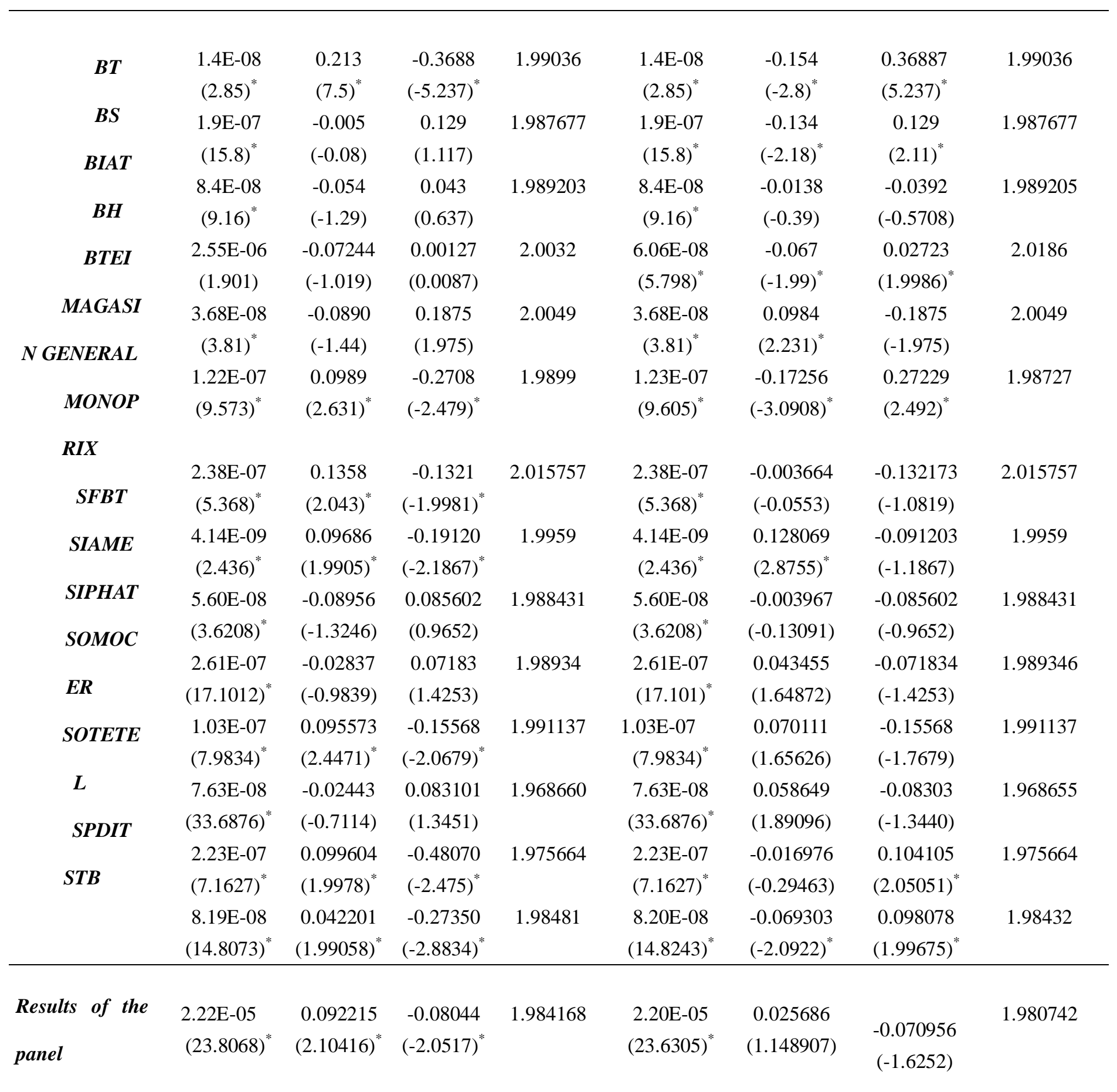


Results show that all the coefficients relating to the variable activity of transaction, measured by the total volume of exchange, are positively significant. Thus, one can affirm the importance of transactions volume in the explanation of the volatility. This highlights the informative contents of the volumes of transactions. As it is shown by G Sahota, B Singh (2016) who stipulates that the positive relation between volume and volatility is primarily due to the informed exchanges the impact of this is evaluated by using a Proxy of private information. Like Liorente idea, Michaely, Saar and Wang (2002) affirm that a high volume of transaction can help to detect the period of informational shocks and, consequently, can get the information that affects the future value of the equity.

It is also noticed that this relation is invariant if the volume of transaction is associated with the transactions of sales or the transactions of purchases. This is explained by the fact that the variables initiated purchases and initiated sales are controlled at the level of the first regression. Thus, these variables have already been taken into account for the estimate of the values of volatility.

The analysis indicates that not all of these coefficients are statistically significant. This result is logical and carries financial implications.

Initially, we will focus on the analysis of the relation between the volatility of the flows and the direction of exchange for the case or the coefficient $\delta_{i 1}$ is not statistically significant. Indeed, an insignificant coefficient implies that one must reject the assumption that this coefficient is different from zero and accept the assumption that it is null. However, if $\delta_{i 1}$ is null, this signifies that the coefficient $\delta_{i 0}$ is used in order to study the impact of the equities price variation on the future volatility. However, table (2) shows that $50 \%$ of the equities in our sample present an insignificant coefficient $\delta_{i 1}$. One may notice that all the coefficients $\delta_{i 0}$ are negative. A negative $\delta_{i 0}$ shows the effect of the asymmetry of volatility. As this result means that an increase in the last non-anticipated return (measured by the residue of the equation (1)) induced a reduction of volatility, so a fall of the last non-anticipated return increases volatility. This affirms that the asymmetry of volatility changes according to the flow of exchanges. This enhances the fact that the phenomenon of the asymmetry of volatility is connected to the variation in the time of returns.

Secondly, we will study the case or the coefficients $\delta_{i 1}$ are significant. The results show that $50 \%$ of the equities in our ample present a significant coefficient $\delta_{i 1}$ when the activity of the transaction is measured by sales; then, this coefficient is significant only for $42 \%$ of the equities if the measurement is the transactions of purchase. Again, if the adopted measure is the transactions of sales, all the coefficients $\delta_{i 1}$ are a negative sign while the sign of $\delta_{i 0}$ becomes positive. In fact, a negative $\delta_{i 1}$ suggests that the phenomenon of asymmetry of volatility is variable in time; precisely, the asymmetry of volatility varies with the transactions of sales. This shows that sales transactions at the date (t-1) associated with positive returns (negative) induce a fall (increase) of volatility at the date (t). Otherwise, in the presence of negative returns, sales generate an increase in the volatility of equities for the next day; whereas, in the presence of positive returns, the transactions of sales induce a fall of volatility during the next day. However, a negative $\delta_{i 1}$ with a

positive $\delta_{i 0}$ suggests that the asymmetry of volatility is entirely allocated to the interaction between the transactions of sales and volatility. However, the examination of the results relating to the measurement of the activity of transactions by the initiated purchases shows that the coefficients $\delta_{i 1}$ are statistically significantly positive. Similarly, 
this result suggests that in the presence of positive returns, the transactions of purchases increase volatility; whereas, the transactions of purchases associated with negative returns reduce volatility.

This research shows that the impact of exchange direction differs according to the market trend. Indeed, if the returns are positive, the transactions of sale (of purchase) generate a fall (increase) of volatility, but they induce an increase (drops) of volatility if the returns are negative. This result stresses the importance of the exchange direction in the explanation of asymmetric volatility.

\subsection{The Impact of «Herding \& Contrarian Trades»}

Evoking that the "herding trades" are defined by the transactions carried out by the irrational investors who buy when returns are positive and sell when returns are negative and, consequently, involve a deviation of the equities prices from their true values; whereas, the "contrarian trades" are the transactions of the rational investors who buy when returns are negative and sell when returns are positive, and bring the equities prices back to their fundamental values. We try to distinguish the impact of this type of investors on volatility of equities quoted in the Tunisian financial market. The results are presented on Table 3 .

Table 3. Impact of «herding \& contrarian trades»

$$
\begin{aligned}
& \left|\varepsilon_{i t}\right|=\phi_{i}+\psi_{i} M_{t}+\sum_{k=1}^{12} \rho_{i k}\left|\varepsilon_{i, t-k}\right|+\varphi_{i} N T_{i, t} \quad\left|\varepsilon_{i t}\right|=\phi_{i}+\psi_{i} M_{t}+\sum_{k=1}^{12} \rho_{i k}\left|\varepsilon_{i, t-k}\right|+\varphi_{i} N T_{i, t}
\end{aligned}
$$

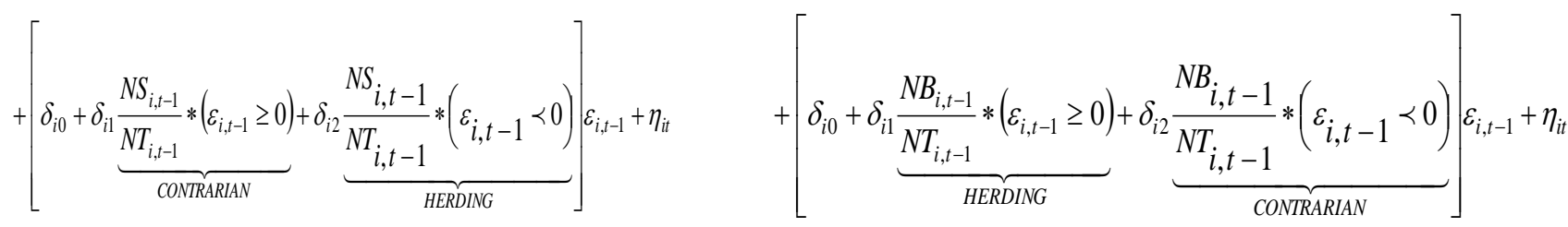

$\begin{array}{ccccccc}\varphi_{i} & \delta_{i 1} & \delta_{i 2} & \varphi_{i} & \delta_{i 1} & \delta_{i 2}\end{array}$

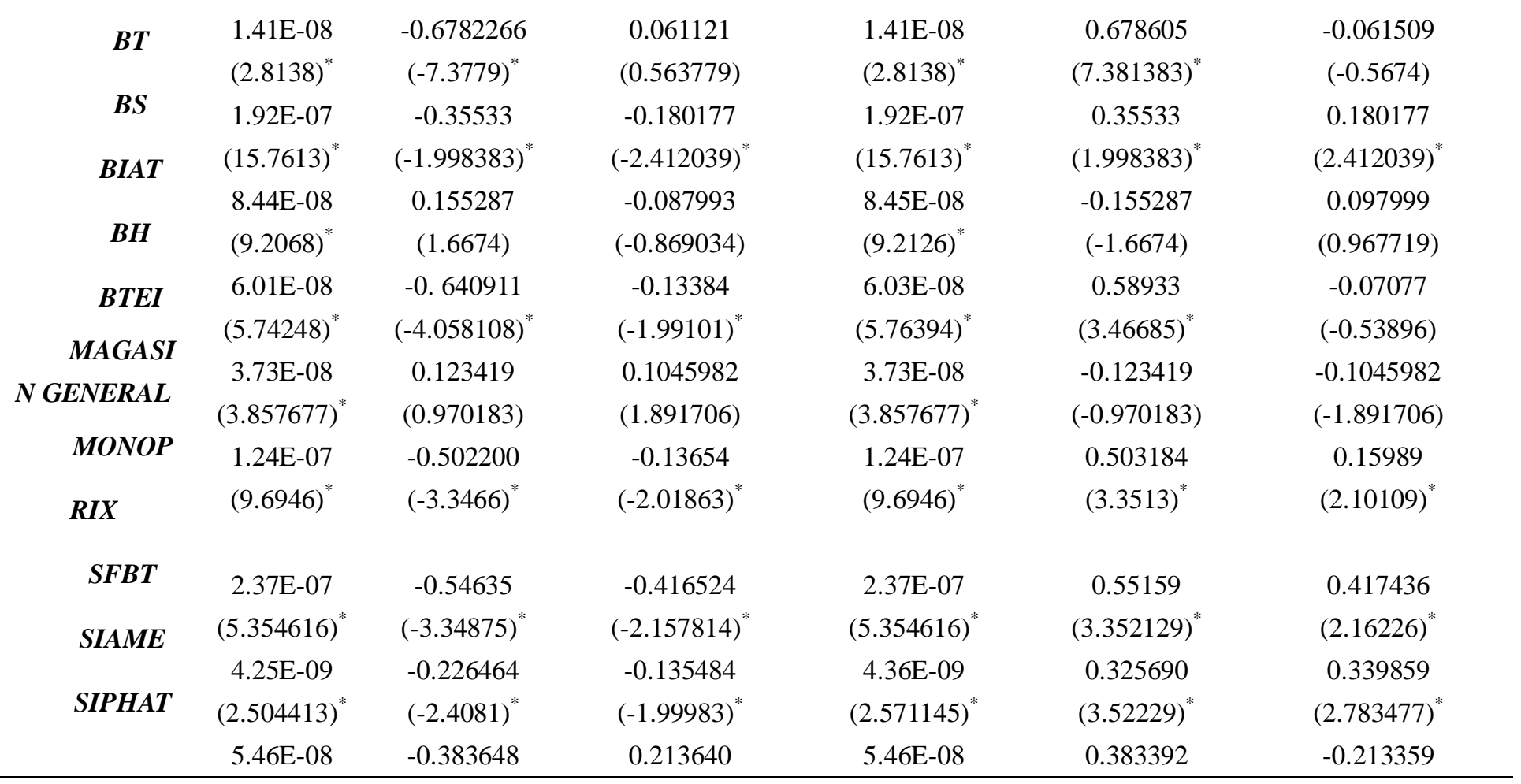




\begin{tabular}{ccccccc}
\hline \multirow{2}{*}{ SOMOC } & $(3.537270)^{*}$ & $(-3.066034)^{*}$ & $(1.703939)$ & $(3.537270)^{*}$ & $(3.063958)^{*}$ & $(-1.701751)$ \\
\multirow{2}{*}{$\boldsymbol{R}$} & $2.61 \mathrm{E}-07$ & 0.004668 & 0.139646 & $2.61 \mathrm{E}-07$ & -0.003011 & -0.141321 \\
\multirow{2}{*}{ SOTETEE} & $(17.0795)^{*}$ & $(0.065776)$ & $(1.958288)$ & $(17.09233)^{*}$ & $(-0.042428)$ & $(-1.981864)$ \\
& $1.08 \mathrm{E}-07$ & -0.249479 & 0.015077 & $1.08 \mathrm{E}-07$ & 0.249479 & -0.015077 \\
$\boldsymbol{L}$ & $(8.0158)^{*}$ & $(-2.16198)^{*}$ & $(0.105929)$ & $(8.0158)^{*}$ & $(2.16198)^{*}$ & $(-0.105929)$ \\
\multirow{2}{*}{ SPDIT } & $1.97 \mathrm{E}-05$ & -0.298835 & -0.25842 & $7.61 \mathrm{E}-08$ & 0.280627 & 0.11341156 \\
\multirow{2}{*}{ STB } & $(37.40404)^{*}$ & $(-2.872347)^{*}$ & $(-2.25413)^{*}$ & $(33.61017)^{*}$ & $(3.239241)^{*}$ & $(2.013693)^{*}$ \\
& $2.26 \mathrm{E}-07$ & 0.074044 & -0.207761 & $2.26 \mathrm{E}-07$ & -0.074044 & 0.207761 \\
& $(7.23655)^{*}$ & $(0.552120)$ & $(-1.995458)^{*}$ & $(7.23655)^{*}$ & $(-0.552120)$ & $(1.995458)^{*}$ \\
& $8.18 \mathrm{E}-08$ & 0.150459 & -0.068881 & $8.19 \mathrm{E}-08$ & -0.152898 & 0.06982 \\
& $(14.7933)^{*}$ & $(1.760533)$ & $(-0.69242)$ & $(14.81150)^{*}$ & $(-1.784433)$ & $(0.701831)$ \\
\hline \multirow{2}{*}{ Results of the } & $1.26 \mathrm{E}-07$ & -0.38276 & -0.039208 & $1.26 \mathrm{E}-07$ & 0.38972 & 0.041441 \\
panel & $(28.5756)^{*}$ & $(-2.881175)^{*}$ & $(-0.785414)$ & $(28.5756)^{*}$ & $(2.897012)^{*}$ & $(0.829968)$ \\
\hline
\end{tabular}

All the coefficients related to the size of exchange are significantly positive. This, in fact, highlights the importance of the volume of transactions in the explanation of returns volatility. This positive relation is explained by the informative contents of transactions volumes in explaining volatility. Thus, it should be noted that if the activity of the transactions is measured by the frequency of transactions instead of the volume of exchange, the results remain unchanged. But we should not deny that the coefficient of adjustment is higher in measuring the frequency of transactions. This is due to the fact that the informative contents of the number of transactions are higher than those of the size of exchange since an informed investor can split a large sized transaction into several small sized ones. This result corroborates the results obtained by N Blasco, P Corredor, S Ferreruela (2012).

However, the analysis of " $\mathrm{t}$ " of student related to $\delta_{i 1}$ shows that these coefficients are significant only for $65 \%$ of the equities included in our sample.

If we consider the case in which the exchange direction is specified by sale transactions, we notice that all the significant coefficients $\delta_{i 1}$ are negative. In other words, "contrarian sell trades" induce a fall in volatility. Indeed, this result is explained by the fact that these transactions are carried out by the rational investors who sell when the returns are positive and buy when the returns are positive. Thus, they bring the equities prices back towards their fundamental value and, consequently, they generate a reduction of volatility. However, this negative coefficient associated with a non-anticipated positive return leads to a fall of volatility. This result coincides with the previous explanation of this type of investor. What is more, we notice that the coefficients $\delta_{i 2}$ are significantly negative for $50 \%$ of securities in our sample. Accordingly, we can assert that the transactions sales of the irrational investors, named "herding sell trades", contribute to the increase the price volatility. Indeed, the irrational investors or "noise traders" sell when the returns are negative. This swerves the securities prices from their true values and, consequently, leads to increase volatility. In this respective, researchers explain why this type of transactions has a reverse impact on the prices with that of the quality of information and, consequently, increases the uncertainty of the investors about the true value of the equity and, by the way, generate an important volatility. Our results affirm this intuition since the negative sign of the coefficient associated with non-anticipated negative return increases volatility. One can, thus, conclude that "herding sell trades" lead to an increase in volatility, whereas "contrarian sell trades" induce a fall of volatility. 
If the exchange direction is measured by the purchases, the results remain unchanged. In fact, we notice that the coefficients $\delta_{i 1}$ are significantly positive for $65 \%$ of the equities. However, this coefficient is relative to the "herding buy trades". These transactions are assumed to be carried out by the irrational investors who buy when the returns are positive and sell when the returns are negative. Thus, the purchases of the irrational investors move the prices from their true values and lead to an increase in volatility. Therefore, a positive coefficient $\delta_{i 1}$ associated with a positive return means that the purchases of the "herding traders" increase volatility. The analysis of the coefficient $\delta_{i 2}$ shows that $50 \%$ of the equities are significantly positive coefficients. However, these coefficients are relative to the "contrarian buy trades" which are the operations of purchases of the rational investors who buy when the returns are negative.

Thus, a positive coefficient $\delta_{i 2}$ associated with a non-anticipated negative return means that the transactions of purchases of the rational investors decrease volatility. Thus, one may conclude that the "contrarian buy trades" reduce volatility, whereas the "herding buy trades" increase volatility. This is explained by the fact that the "contrarian trades" stabilize the prices but the "herding trades" destabilize the prices. These results affirm that sales and purchases transactions are at the origin of the volatility asymmetry.

One may also remark that the coefficients $\delta_{i 1}$ are significant for $65 \%$ of the equities but the coefficients $\delta_{i 2}$ are significant only for $50 \%$ of the equities. In this, one can say that the sales or the purchases associated with positive returns have a higher impact on volatility than that of the sales associated with negative returns. The results can be summarized as following:

\begin{tabular}{lllll}
\hline Non-anticipated returns & Transactions of sales & Volatility & Transactions of purchases & Volatility \\
\hline Positive & Contrarian & Decrease & Herding & Increase \\
Négative & Herding & Increase & Contrarian & Decrease \\
\hline
\end{tabular}

\subsection{Exchange Direction, Informed Investor, Uninformed Investor and Volatility}

It is intuitively suggested that the transactions of the informed investors bring the prices back to their fundamental values and lead to a reduction of volatility; whereas, those of the uninformed investors draw the prices aside from their true values and lead to an increase in volatility. Hellwig (1980) affirms that the negotiation of a strongly volatile equity indicates that there are uninformed investors in the market. Analogically, the increase in volatility is an index of the small number of informed investors in the market. Thus, the larger the number of the informed investors is, the more precise the signal will be, and its impact on the price is pronounced and, generates consequently, a reduction of volatility. In this, one can say that the transactions of the informed investors are identical to those of the "contrarian trades" while those of the uninformed investors are identical to those of the "herding trades". In order to distinguish the impact of the transactions of the informed investors from that of the exchanges of the uninformed ones, we chose the method of Campbell, Grossman and Wang (1993) and Avramov, Chordia and Goyal (2006). Indeed, the used method is the study of the auto- correlation test. The very test suggests that the previous returns due to the exchanges of the informed investors should not be related to the future return, while those relating to the transactions of the uninformed investors are related to the future return. Thus, this test suggests the absence of an auto- correlation between the last and future returns for the transactions of the initiates, whereas this auto- correlation exists between the returns of the uninformed investors' transactions. The results of this test are presented in Table 4. 
Table 4. Informed investor, uninformed investor and volatility

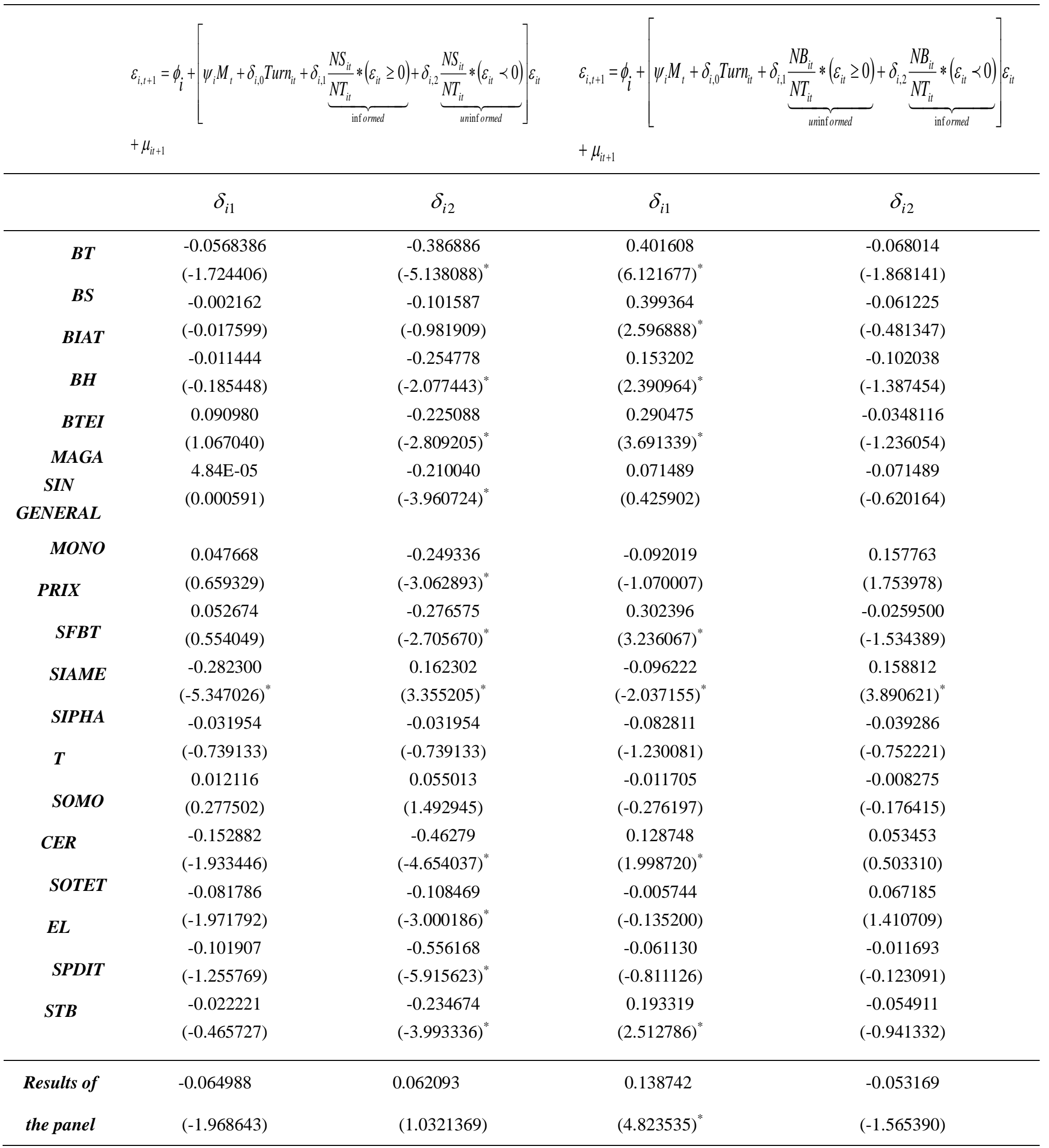


The analysis of these results shows that, for sale transactions, $92 \%$ of the equities are an insignificant coefficient $\delta_{i 1}$.

So, $\delta_{i 1}$ is assumed to be equal to zero. This indicates that there is an absence of an auto- correlation of returns for the transactions of sales carried out by the informed investors. This result means that the sales of the informed investors do not involve a correlation of returns of individual equities. This is explained by the fact that the transactions of sale of the informed investors directly bring the equities flows back towards their true value. Therefore, they immediately reach their equilibrium price. Accordingly, the future return will be independent of the previous return since it depends only on the new information held by the informed investor. One may also notice that the coefficient $\delta_{i 2}$ is significantly negative for $70 \%$ of the equities. So, there exists a negative auto- correlation between the returns. The sales, thus, carried out by the uninformed investors lead to a negative auto-correlation of the returns. This result is consistent with Campbell, Grossman and Wang (1993) who stipulate that the occurrence of the inversion of the prices is related to the absorption of the suppliers for the liquidity of the sales of the uninformed investors. This result is explained by the fact that the sales of these investors draw the equities flows from their fundamental value. Therefore, the prices need time to reach their equilibrium levels. This induces an inversion of the prices which results confirm a negative auto- correlation of returns.

If we care about purchase, we notice that the coefficients $\delta_{i 1}$ are significantly positive for $50 \%$ of the equities. Hence, we may confirm that the purchases by uninformed investors involve a positive auto- correlation of the equities returns. This positive correlation is explained by the positive feedback of the uninformed investors. But the coefficients $\delta_{i 2}$ are significant for $92 \%$ of the equities. Then, they are assumed to be null. This reveals the absence of an auto-correlation between the returns of the transactions of the informed investors. This result is explained by the absence of the phenomenon of the investors' feedback.

In short, we can conclude that the transactions of the informed investors do not involve an auto- correlation of the returns. While purchases (sales) transactions of the uninformed investors induce a positive auto- correlation (negative) of returns. The results are summarized by the following table:

\begin{tabular}{ccccc}
\hline $\begin{array}{c}\text { Non-anticipated } \\
\text { returns }\end{array}$ & Transactions of sales & Serial correlation & $\begin{array}{c}\text { Transactions of } \\
\text { purchases }\end{array}$ & $\begin{array}{c}\text { Serial } \\
\text { correlation }\end{array}$ \\
\hline Positive & Informed investors & Negative & Uninformed investors & Positive \\
Négative & Uninformed investors & absence & Informed investors & Absence \\
\hline
\end{tabular}

\section{Conclusion}

In this research, we presented the informative role of the exchange direction as a measurement of the transactions activity omitted by most researchers. Indeed, most researches measure the activity of transaction through the volume of exchange. But considered alone is insufficient because it can hide some very important aspects since it does not offer the ability to see the direction of exchange, i.e. whether there is a purchase or a sale, knowingthat each of these two cases holds its specific implications about price and liquidity.

The orders imbalance urges the market maker to revise price whether in rise or in fall so that he can adjust his position. This enhances the importance attached to the imbalance of orders in the relation between the activity of transactions and price volatility. The theories ensure that the informational contents of the exchanges increase linearly with the frequency of transactions, less than the increase according to the size of exchange. In addition, they have concluded 
that the mechanism of pricing is related to the process of the advent of the private information by the detection of the informative contents through the frequency of exchanges and the imbalance of orders. According previous research the reactions of investors depend on the market trend and they affirmed that the imbalance of orders significantly explains the market returns; while the average range of estimate used as a measurement of liquidity does not have any explanatory power over the market returns.

Throughout this study, we based our empirical investigation on listed securities in the Tunisian market. Indeed, we attempted to determine the impact of the activity of transaction, measured by the volume of exchange, on the returns volatility. Moreover, we focused on the study of the role of the exchange direction in explaining the volatility of the flows and on the asymmetry of volatility.

Therefore, we identified the exchange direction according the method called "Augmented Tick Test" (ATT). Such method is appropriate to the Tunisian financial market.

As a matter of fact, the relation between the transactions of purchases and return is significantly positive. This result indicates that the purchases involve an increase in the returns. But if there are transactions of sales, the relation with the returns will reverse and become negative. Thus, the initiated sales affect the returns negatively. This is explained by the fact that the transactions of sale represent a bad signal, whereas purchase transactions are interpreted as a good signal. Moreover, the results show that the relation between the volume of transactions and the volatility is significantly positive. Thus, one can affirm the importance of the volume of transaction in the explanation of the volatility of the prices. This highlights the informative contents of the volumes of transactions. Thus, it should be noted that if the activity of transactions is measured by the frequency of transactions instead of the volume of exchange, the results remain unchanged. But it should be noted that the coefficient of adjustment $R^{2}$ is higher for the frequency measurement of the transactions. This is due to the fact that the informative contents of the number of the transactions outweigh the size of exchange; since an informed investor can split a big sized transaction into several transactions of low or medium size and, consequently, camouflages his position.

The examination of the exchange direction on the volatility affirms that in the presence of negative returns the transactions of sale generate an increase in the volatility for the next day; whereas; in the presence of positive returns, the transactions of sales involve a fall of volatility during the next day. However, the examination of the results concerning the measurement of the activity of transactions by the initiated purchases shows that in the presence of positive returns the transactions of purchases increase volatility, whereas the transactions of purchases associated with negative returns reduce volatility. Thus, one can affirm that the direction of exchange is at the origin of the phenomenon of asymmetry of volatility.

Next, we distinguished the "contrarian trades" and the "herding trades". The results show that the "contrarian buy trades" reduce volatility, whereas the "herding buy trades" increase volatility. "Herding sell trades" involve an increase in volatility, whereas "contrarian sell trades" induce a fall of volatility. This is explained by the fact that the "contrarian trades" stabilize the prices, but the "herding trades" destabilize the prices.

The given assertions, in fact, enable us to distinguish the transactions of the informed investors from those the uninformed investors. The results show that the transaction of the informed investors does not induce an auto-correlation of the returns. Nevertheless, the transactions of purchases (of sales) of the uninformed investors induce a positive auto-correlation (negative) of the returns.

\section{References}

Anshuman, V. R., Brennan, M., Chordia, T., \& Subrahmanyam, A. (2001). Trading activity and expected stock return. Journal of Financial Ecnomics, 59(1), 3-32. https://doi.org/10.1016/S0304-405X(00)00080-5

Avramov, D., Chordia, T., \& Goyal, A. (2006). Liquidity and autocorrelations in individual stock returns. The Journal of Finance, 61(5), 2365-2394. https://doi.org/10.1111/j.1540-6261.2006.01060.x

Blasco, N., Corredor, P., \& Ferreruela, S. (2012). Does herding affect volatility? Implications for the Spanish stock market. Quantitative Finance, 12(2), 311-327. https://doi.org/10.1080/14697688.2010.516766

Chan, K., \& Fong, W. M. (2000). Trade size order imbalance and the volatility - volume relation. Journal of Financial Economics, 57(2), 247-273. https://doi.org/10.1016/S0304-405X(00)00057-X

Chordia, T., \& Subrahmanyam, A. (2003). Price formation with autocorrelated order flow: theory and evidence. https://doi.org/10.2139/ssrn.336060

Chordia, T., \& Subrahmanyam, A. (2004). Order imbalance and individual stock returns: Theory and evidence. Journal of Financial Economics, 72(3), 485-518. https://doi.org/10.1016/S0304-405X(03)00175-2 
Guojun, W. (2001). The determinants of asymmetric volatility. The Review of Financial Studies, 14(3), 837-859. https://doi.org/10.1093/rfs/14.3.837

Hu, S. Y., \& Chan, C. (2000). Trade direction in order-driven markets - definition, inference, and evidence. https://doi.org/10.2139/ssrn.250704

Jones, M. J., Kaul, G., \& Lipson, M. L. (1994). Transactions, volume and volatility. The Review of Financial Studies, 7(4), 631-651. https://doi.org/10.1093/rfs/7.4.631

Li, M., Cormick, M. T., \& Zhao, X. (2004). Order imbalance and liquidity supply: evidence from the bubble burst of nasdaq stocks. Journal of Empirical Finance, 12(4), 533-555. https://doi.org/10.1016/j.jempfin.2004.11.001

Miseman, M. R. (2019). The dynamic relationship between trading volume, stock return, and volatility-domestic and cross-country: south Asian markets. Finance, Accounting and Business Analysis (FABA), 26(1), 51-78. https://doi.org/10.1016/S0378-4266(00)00173-4

Naik, P. K., \& Padhi, P. (2015). Stock market volatility and equity trading volume: Empirical examination from Brazil, Russia, India and China (BRIC). Global Business Review. https://doi.org/10.1177/0972150915601235

Naik, P. K., Gupta, R., \& Padhi, P. (2018). The relationship between stock market volatility and trading volume: evidence from south africa. Journal of Developing Areas, 52(1), 99-114. https://doi.org/10.1353/jda.2018.0007

Namitha, K., \& Cheriyan, D. L. (2019). Relationship between liquidity, volatility and trading activity: an intraday analysis of Indian stock market. International Journal of Economics and Financial Issues, 9(1), 17-22.

Ni, Y., Liao, Y. C., \& Huang, P. (2015). MA trading rules, herding behaviors, and stock market overreaction. International Review of Economics \& Finance, 39, 253-265. https://doi.org/10.1016/j.iref.2015.04.009

Pisedtasalasai, A., \& Gunasekarage, A. (2007). Causal and dynamic relationships among stock returns, return volatility and trading volume: Evidence from emerging markets in South-East Asia. Asia-Pacific Financial Markets, Springer. https://doi.org/10.1007/s10690-008-9063-3

Schwert, W. (1990a). Stock market volatility. Financial Analyst's Journal, 46(3), 23-34. https://doi.org/10.2469/faj.v46.n3.23

Schwert, W. (1990b). Stock volatility and the crash of 1987. The Review of Financial Studies, 15(6), 969-981.

Wang, Y. C., Wu, J. L., \& Lai, Y. H. (2018). New evidence on asymmetric return-volume dependence and extreme movements. Journal of Empirical Finance, 45, 212-227. https://doi.org/10.1016/j.jempfin.2017.11.012

\section{Copyrights}

Copyright for this article is retained by the author(s), with first publication rights granted to the journal.

This is an open-access article distributed under the terms and conditions of the Creative Commons Attribution license (http://creativecommons.org/licenses/by/4.0/). 